\title{
Analysis of the Narrative Types of "Metaphor" in Animated Short Films
}

\author{
Hsien-Yuan Chiu, Wei-Lin Chu \\ Graduate School of Visual Communication Design, National Yunlin University of Science and Technology, Taiwan \\ Email: chiou.milkcar@msa.hinet.net,m10732007@yuntech.edu.tw
}

How to cite this paper: Chiu, H.-Y., \& Chu, W.-L. (2019). Analysis of the Narrative Types of "Metaphor" in Animated Short Films. Art and Design Review, 7, 206-224.

https://doi.org/10.4236/adr.2019.74017

Received: October 1, 2019

Accepted: November 2, 2019

Published: November 5, 2019

Copyright $\odot 2019$ by author(s) and Scientific Research Publishing Inc. This work is licensed under the Creative Commons Attribution International License (CC BY 4.0).

http://creativecommons.org/licenses/by/4.0/

(c) (i) Open Access

\begin{abstract}
The most presented storytelling medium of animation and film are images. The narrative messages that viewers obtain through images are much more rigorous than those from dictation or narration. Therefore, the means to construct story context in an animation narrative is more than the intuitive narrative of character language. Message transmission by hints seems to be an important technique of image narrative in a plot. Potential messages involve metaphors in rhetoric. When applied to an image narrative, linguistic techniques have gone beyond the scope of literal modification. Meaning the viewers' cognition and past experiences are also involved in the process of image viewing. Therefore, the metaphors in animated movies are a type of narrative produced by multiple elements, as well as a mode of deduction based on real life. According to the related theories of metaphorical mapping, this study explores the analogical narrative process of images in animation cases, as based on Gentner's structural mapping theory and the blending theory of Fauconnier and Turner. The results of case study show that, in animated movies, analogies are made through similarities in form, meaning the attributes of source and target are blended as the means of metaphor, where the lens movement also contributes to the metaphor of space on the visual psychological level. In summary, this study is expected to serve as a reference for further exploration of the metaphoric narrative of animation in the future.
\end{abstract}

\section{Keywords}

Animated Short Films, Metaphor, Animation Narrative

\section{Introduction}

A metaphor narrative is one of the techniques to describe a plot story, which plays an indispensable role in animated movies. In the film context, in addition 
to the image performance of the main characters, through images, the transmission of hidden messages increases the aesthetic value of the short narrative in the film. At the same time, through the description of a metaphor, the viewers can actively participate in the plot and deduce the story, meaning the image narrative constitutes an interactive media. In fact, every animated movie has the manifestations of metaphor narrative, such as Ratatouille, as produced by Pixar Animation Studios (Figure 1), which used black screen and lines to express the various tastes of delicious foods, and the Castle in the $S k y$, an animation produced by Japanese director Hayao Miyazaki in 2002 (Figure 2), which used two spaces as the hints of human beings' yearning for an imaginary Utopian and the essence of human nature.

From the above, we can see that the director elaborated the characteristics of the event by analogy through the relationship between the scenes, thus, highlighting the importance of metaphors for the rigor of an image narrative. A metaphor is a proper noun in rhetoric, which achieves symbolic links through the process of corresponding patterns by similar psychological analogy (Wen, 2010). There are many related researches on the effect of metaphorical cognition from multiple dimensions, as well as the ways to transmit the meaning by the metaphor from the perspectives of cognitive psychology, semantics, etc. The

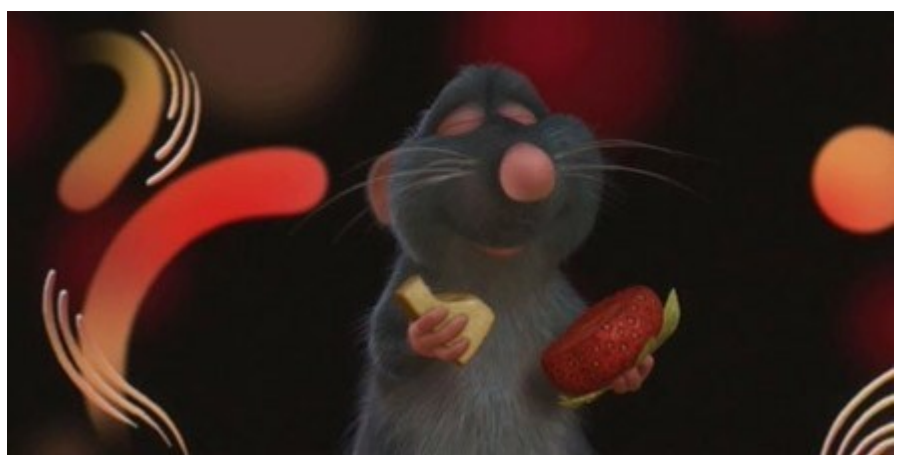

Source: https://www.comicsbeat.com/michel-gagne-and-ratatouille/.

Figure 1. Ratatouille guides through hints in the back lines.

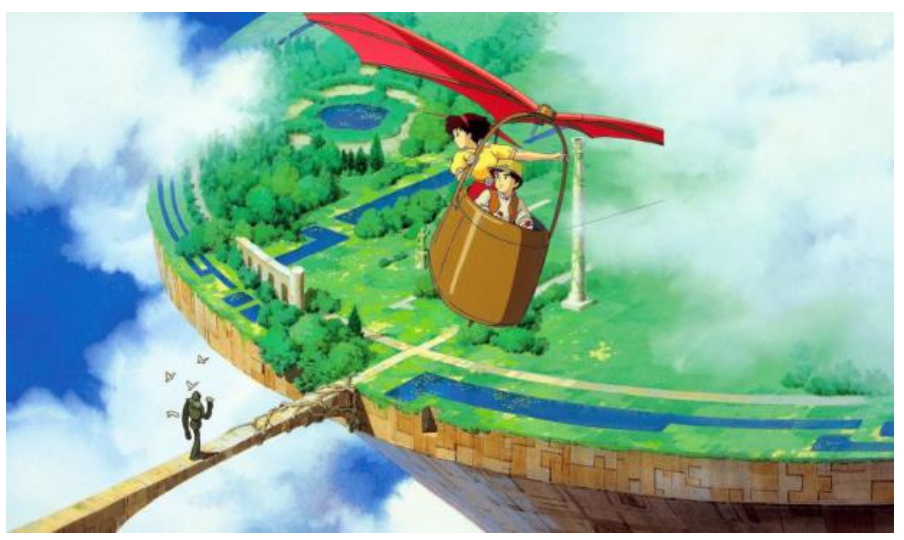

Source: https://ciatr.jp/topics/32054.

Figure 2. Another imaginary space beyond reality in the Space Castle in the Sky. 
most important classic work Metaphors We Live By, as written by George Lakoff and Mark Johnson, put forward the concept of metaphors in 1980, which held that metaphors not only exist in written expression, but also exist in life, thus, extending the dimensions of metaphor research from linguistics to perceptions, including visual sense, auditory sense, tactual sense, etc.

However, in terms of visual sense, in 2008, Charles Forceville proposed a way for images to convey implicit messages, meaning that metaphors may provide non-verbal information through the expression of dynamic images. While a lot of literature has analyzed the image metaphor cases in semiotics and advertisements, it is seldom discussed in the field of animation or film. This study takes the metaphor narrative of animation media as the starting point to explore the metaphor technique of image media. The commonly used theoretical basises of the metaphor are: contrast model, feature salience imbalance, conceptual metaphor theory, blending theory, structural mapping theory, etc. (Wang, 2012). As the purpose of animated film itself is to make viewers feel the link between specific phenomena and practical experience in stylized image manifestations through image narrative, this paper believes that the blending theory and the structural mapping theory are suitable theories for the exploration of the basic framework of image metaphors, where the corresponding image is the metaphor link. Therefore, this study analyzes the symbols and images in animated movies on the basis of the above two theories, and analyzes and summarizes how they are operated and conveyed by rhetorical metaphors and metaphors manifested by image narratives.

This study attempts to analyze the expression technique of metaphors in animation by taking the narrative of animated films as the point of penetration, explores the process of metaphoric reference, and deduces the application of rhetoric in images through literature review. Secondly, this study analyzes the link from the cognition of dynamic images to experience knowledge through a case study of the mapping relationship between multiple attributes and the meanings of images. With award-winning cases as the research samples, this study summarizes the forms and techniques of the expression of metaphoric foreshadowing in animation image narratives, and analyzes its mapping relationship, in order to explore the rigor conveyed by images in animation. The purposes of the study are summarized, as follows:

1) Discuss the application of metaphor rhetoric in animation narratives through literature review.

2) Analyze the image presentation of metaphor narratives in animation and films.

\section{Literature Review}

\subsection{From Metaphor Rhetoric to Image Relationship in Movies}

Rhetoric itself is a means of description, which makes the text closer to the real life state or enables the reader to perceive the essence of the text. In order to 
make the description of the text more precise or more rigorous, different reference methods are used in language to express some abstract states, such as "time is money", "knowledge is power", etc. The advantage of rhetoric is that it enables the meaning of language to be understood without specifying all the details (Gannon, 2001).

Gannon (2001) The point and virtue of particularization is that it enables language comprehension to take place without the need for message to explicitly spell out all the details (p. 12).

Metaphoric rhetoric has a specific way of reference in rhetoric. In 1980, Metaphors We Live By pointed out that metaphors are a part of life that makes artistic expression more diverse. From this, we can see that the technique of metaphors has been applied in linguistics, as well as an expression approach in reality. In the traditional view, metaphor rhetoric can only be used in speech or text, but in fact, metaphors can be expressed by images (Sajaniemi \& Stützle, 2007).

Sajaniemi, J. \& Stützle, T. (2007) Metaphors may appear in several forms. Traditionally they have been verbal, but they can be pictorial, also (p. 457).

In view of the above, the purpose of conveying expression through metaphors is to enable the audience to understand its meaning more concretely. Particularly in the field of animation or films, the metaphor is an indispensable means of narrative aesthetics, which not only gives the manifestation of abstract meaning, but also motivates the viewers to uncover the context of the story, which makes the narrative context deeply rooted in the hearts of the audience through the hidden relationship.

Modern Times, as directed by Chaplin in 1936, begins by describing the background of the working class, and analogizes crowded sheep with workers in the next scene (Figure 3), where the characteristics of sheep and the relationship between the workers in the story describing the same concepts. In the analogy process of a metaphor, the common attributes of analogy provide the key reference points. In the application of a metaphor, there are common similarities between the objects and the base representation, while individual attributes must be left behind in the mapping process (Gentner, 1983).

Gentner (1983). If the base representation includes concrete objects whose

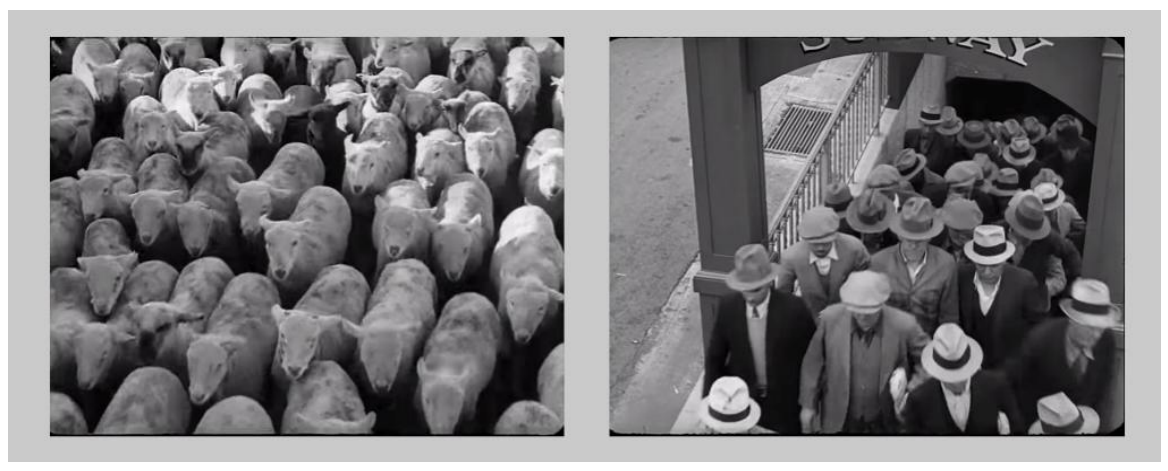

Source: https://www.youtube.com/watch?v=HAPilyrEzC4.

Figure 3. Analogy between the first and the second scenes of Modern Times. 
individual attributes must be left behind in the mapping, the comparison is an $\operatorname{analogy}$ (p. 161).

It is generally acknowledged that sheep are characterized by obedience, cleanliness, etc. Even the Bible used the metaphor of a shepherd seeking sheep to refer to the relationship between Jesus and the people. In this movie, the traits of workers are obedience to superiors' orders and continuously working in an unquestioning manner. In The Cambridge Handbook of Metaphor and Thought, Gibbs Jr. and Raymond W proposed that, after the extended meanings are found through the analogical relationship of a Structure-Mapping Engine (SME), it must also go through the following three discrimination steps: 1) the alignment process of literal meaning; 2) projection of the inference from base to target; 3) directional comprehension of the extended meaning of the metaphor.

- Metaphor comprehension begins with a symmetric (nondirectional) alignment process.

- If an alignment is found, then further inferences are directionally projected from base to target.

- Thus, directionality in metaphor comprehension arises after the initial stage of processing.

(Gibbs Jr., 2008: p.112)

The literal meaning is the original attribute of the object itself. When it comes to dynamic media, the meaning of the scene can be perceived directly. Therefore, it is necessary to analyze the original attributes of the sheep and workers in this case. This paper believes that the analysis of a single picture is not enough to explain the overall meaning of the scene, but must be inferred through the relationship of the image meaning in the neighboring sequence, i.e. the neighboring scenes in the lens. The traits of sheep and workers are analyzed in Table 1.

The table summarizes the relationship between the original attributes and artistic conception. The form, quantity, and composition of the original attributes are expressed with similar techniques; therefore, viewers can easily identify the

Table 1. Attribute analysis of sheep and workers.

\begin{tabular}{|c|c|c|c|}
\hline & Analysis item & Sheet & Works \\
\hline \multirow{4}{*}{$\begin{array}{l}\text { Original } \\
\text { attributes }\end{array}$} & Lifestyle & Moving in herds & Operating in groups \\
\hline & Traits & $\begin{array}{l}\text { Aimlessly obedient; only } \\
\text { moving forward when driven } \\
\text { by shepherds }\end{array}$ & $\begin{array}{l}\text { Operate in accordance with } \\
\text { instructions from superiors, lack } \\
\text { thinking ability, and act in } \\
\text { accordance with instructions }\end{array}$ \\
\hline & Guide & Shepherd & Boss \\
\hline & Image composition & Moving forward in a herd & Moving forward in a group \\
\hline $\begin{array}{l}\text { Artistic } \\
\text { conception } \\
\text { analysis }\end{array}$ & Lens description & $\begin{array}{l}\text { The first scene of the movie, } \\
\text { followed by the scene of the } \\
\text { workers approaching the } \\
\text { work place }\end{array}$ & $\begin{array}{l}\text { The second scene of the movie, } \\
\text { followed by continuous scenes of a } \\
\text { large number of workers going to } \\
\text { the work sites of the factories, } \\
\text { clocking in, etc. }\end{array}$ \\
\hline
\end{tabular}


strong correlation between the two scenes. According to Eco's point of view, a symbolic communication system is a communicational framework that conveys the "code", which is regarded as the transference of symbolic messages in communication, and shares some properties during the transference (ECO, 1976).

ECO (1976). Therefore a non-significant system is called a "code" by a sort of metonymical transference, being understood as part of a semiotic whole with which it shares some properties (p. 38).

Accordingly, in the case, messages have already been transformed in the form of symbolic representation, while the individual attributes have been left behind in the metaphor mapping, as described by Gentner. Furthermore, in the metaphoric relationship, the extended meanings associated with the original attributes must be searched; however, in film semiotics, the extended meanings can be divided into denotation and connotation. Denotation refers to the entire narrative, including the presentation of narrative elements, the description of people, things, objects, time, and space, all of which are the scope of discussion of denotation (ECO, 1990). According to the analysis of the above table, denotation is also the intuitive discrimination of the original attributes, as well as the basis of the metaphor. Connotation, on the other hand, refers to the overall meaning arising from the denotative symbols, as proposed by Metz in the case of Que viva México (Metz, 1964).

Metz (1964). Le langage esthétique a pour signifiant la totalité signifiante-signifiée d un langage premier ( lanecdote, le motif) qui vient s' emboîter en lui (p. 83).

Summarizing the theories proposed by Gibbs Jr. and Raymond W, as well as the denotation and connotation mentioned above, denotation in extended meaning refers to the expression of literal meaning (original attributes). It is worth noting that, according to literature, a metaphor as a narrative is a discrimination based on a general phenomenon. In short, a metaphor narrative is not defined only on the basis of a single phenomenon; instead, it conducts element analogy based on the narrative content in the sequence of the scenes. By editing of the same lens position and composition, Chaplin described the sheep-like state of the workers directly from form similarity, implying that the workers are forced to work aimlessly. He also showed the common relationship between the workers and the sheep, and highlighted their similarities through the pattern and signifier of video pictures. The above analysis confirms the extended meanings described by Gibbs Jr., Raymond W, and Eco, meaning the metaphor is a very important foundation for the nature of original attributes. Furthermore, metaphorical performance is a comprehensive target and base of the whole (Wang, 2012). Therefore, this paper analyzes the mapping relationship and the signifying process of extended meanings in the next chapter.

\subsection{Operation Process of the Extension of Metaphor Mapping in Animated Films}

One theory of the denotation of metaphors to make deductions using the space 
blending theory, as proposed by Fauconnier and Turner, which states that hidden messages are formed by mapping between two different inputs into the final blended space (Fauconnier \& Turner, 2008). Secondly, Gentner's exposition put forward that the process of mapping comparison in metaphors is divided into three stages: first, breaking down and analyzing similarities between sources and objects to make preliminary matching of their relationship; secondly, combining cluster models (called "kernels") into structures for comparison; and thirdly, dividing the combined kernels into one or more maximal structures as the result (Markman \& Gentner, 2000).

Stage 1: Local matches.

Stage 2: Structural coalescence into consistent mappings.

Stage 3: Small structures combined into maximal interpretation; candidate inferences (Markman \& Gentner, 2000: p. 508).

Gentner further proposed the principle of analogy in two domains: analogy shall be based on the relationship between the source and the object, rather than just the attributes of the objects; the specific relationship is determined by the overall analogy system (Gentner, 1983).

Gentner (1983). Two mapping principles are described: (a) Relations between objects, rather than attributes of objects, are mapped from base to target: and $(b)$ The particular relations mapped are determined by systematicity as defined by the existence of higher-order relations (p. 155).

Both the blending theory and the mapping theory are metaphor theories based on the mapping of corresponding attributes. In the analysis of animated movie metaphors, the corresponding relationship between phenomena must be explored and summarized using the mapping concept. The author summarizes the analysis of the two theories in Table 2 for subsequent theoretical construction.

Both the blending theory and structural mapping theory discuss the analogy process of metaphoric analogy, and their viewpoints reveal two metaphor traits: first, the blending theory emphasizes that, besides the mapping of original attributes, other channels are also involved in the process to construct the final blended space; the mapping theory explains that the analogy is made based on the screened concepts and combined in the mapping process. To sum up the above theories, a metaphor is a process of analogy by selecting suitable elements, and then, combining the relevant experience or associative concepts with the source and target domain. Therefore, to induce metaphorical conditions, this paper made a case study based on the theoretical model to explore the techniques in animated movies.

\section{Research Method}

\subsection{A Case Study of the Metaphor Rhetoric in Film Images}

Balance is a silent animated short film that won the 1989 Academy Award for Best Animated Short Film. Directors Christoph Lauenstein and Wolfgang Lauenstein constructed a space to maintain a balance of gravity, as based on the 
Table 2. Comparison between the blending theory and structural mapping theory.

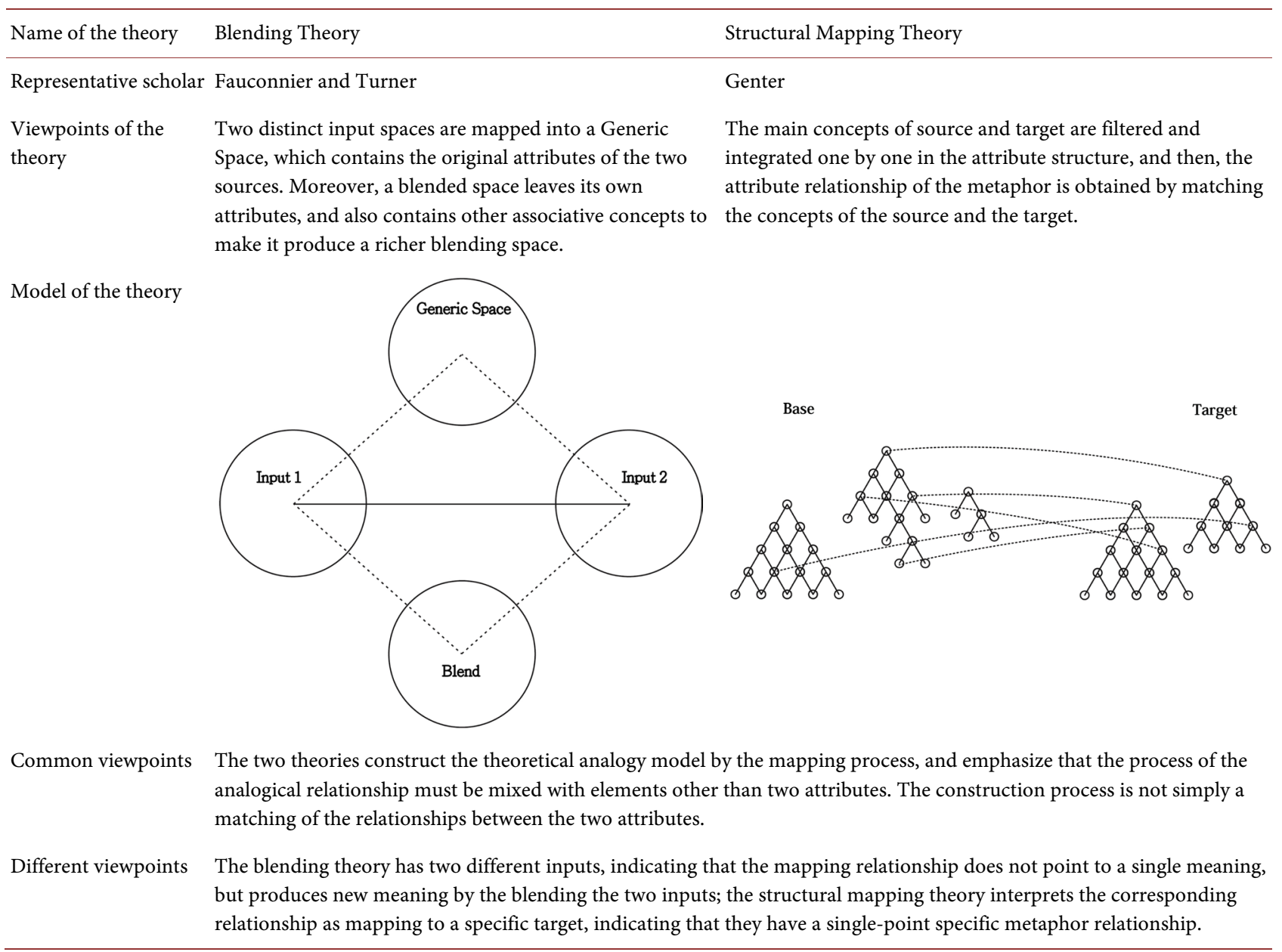

concept that the surviving characters must maintain balance between each other. The treasure box in the narrative implies the benefit or power, etc. desired by people. The process of fighting between the characters reveals different aspects of human nature, while the symbols of the treasure box and unbalanced space are metaphoric references to interests and environments in real life. The author deduced the metaphoric elements in the plot, as shown in Table 3.

The cognition of a metaphor is not random, but based on the experience of natural phenomena, or social or cultural cognition, which is enough for metaphor cognition (Lakoff \& Johnsen, 2003).

Lakoff, G. \& Johnsen, M. (2003). Such metaphorical orientations are not arbitrary. They have a basis in our physical and cultural experience (p. 15).

Furthermore, language is a system of social symbols, while speech is the method of expression that individuals reorganize according to broad vocabulary (Chi, 1992). As the meaning of treasure box in experience is wealth, money, assets, resources, rights, interests, etc., after screening out the most reasonable metaphoric reference of the narrative content according to the broad sense, this paper conducted clustering and matching according to Gentner's theoretical model (Figure 4). 
Table 3. Inference of mapping between base and target.

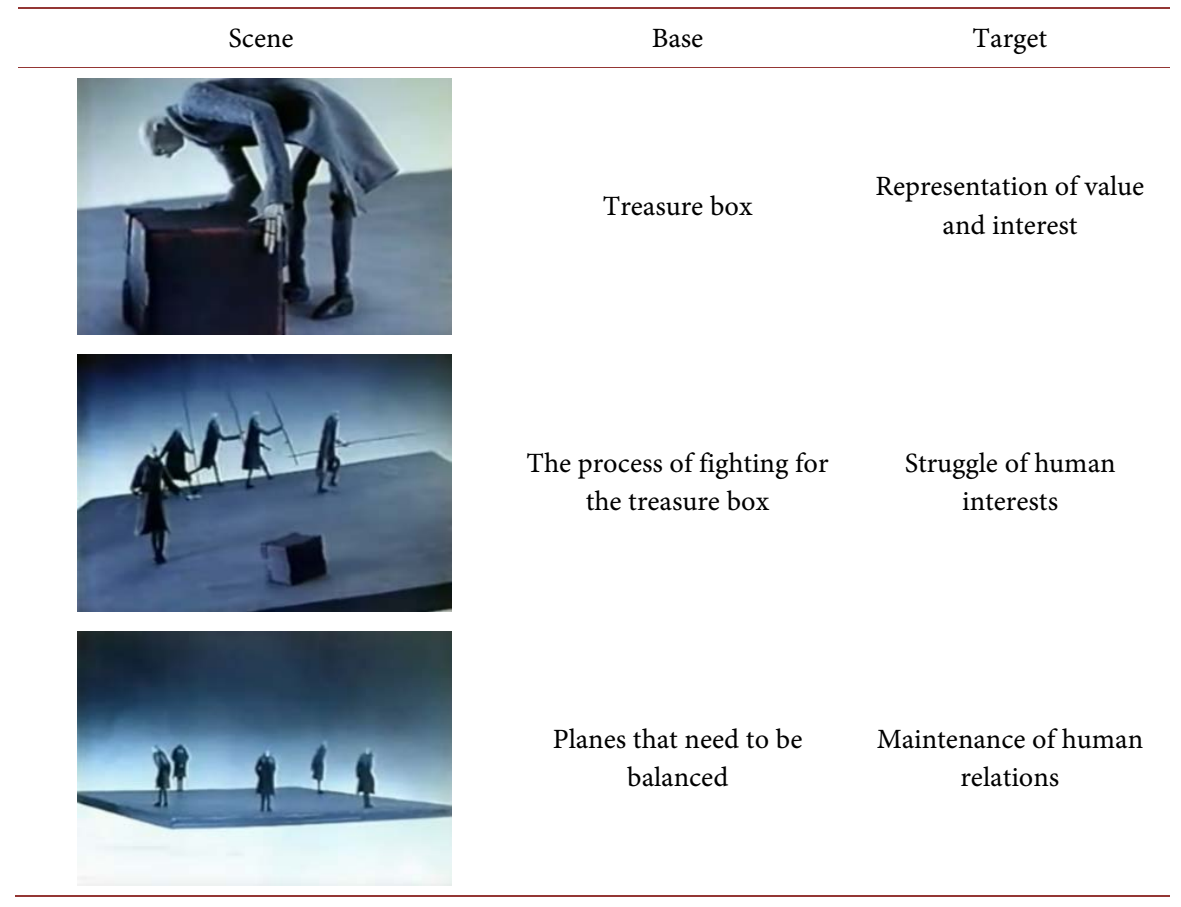

Source: https://www.youtube.com/watch?v=PADVHR-_wOs.

Base

Target

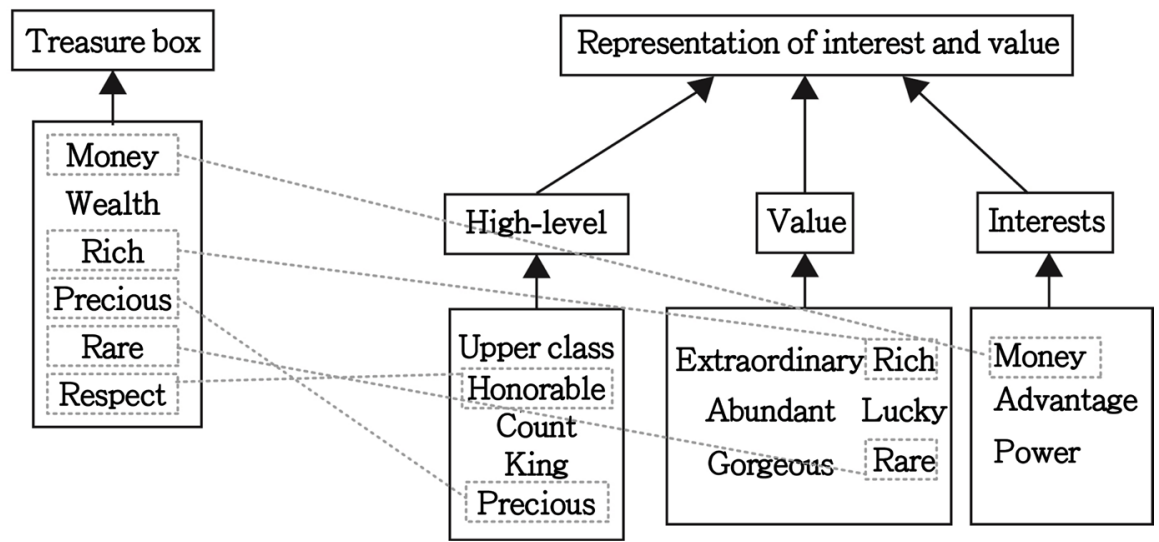

Source: Compiled by this study.

Figure 4. Mapping analysis of treasure box in Balance.

From the inference of Figure 4, it is concluded that the treasure box is in line with the referent in the story, while the deduction that the referent is the "representation of value and interest" is defined by the system-based or up-and-down structure, as proposed by Gentner. The treasure box in the film is positioned as a representation of rarity and preciousness, which is defined by the five characters' fighting for the only interest (Table 4).

The description of the front and back pictures is intended to construct the symbolic meaning of the referent of the metaphor, and the representative meaning 
Table 4. The process of fighting for the treasure box.

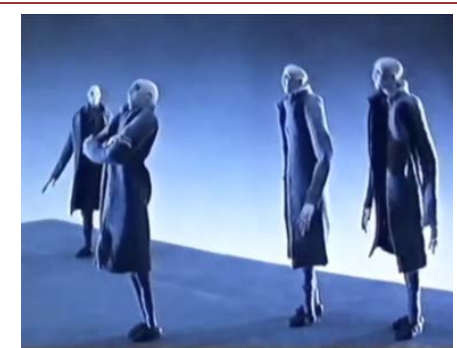

1. One of the characters intentionally stands 2 . Those who were originally close to the treasure forward, intending to force those close to the treasure box to stay away from it.

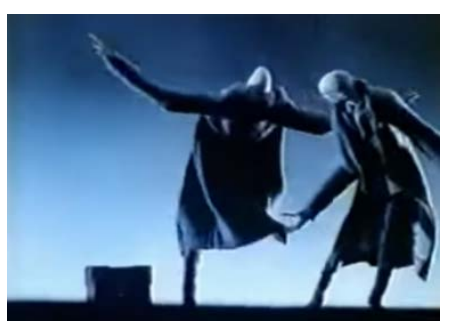

4. When the character who wants the 5 . The two characters begin to quarrel and struggle treasure box keeps moving forward, the character who was close to the treasure box does not want him to succeed, so he takes the opportunity to pull his leg.

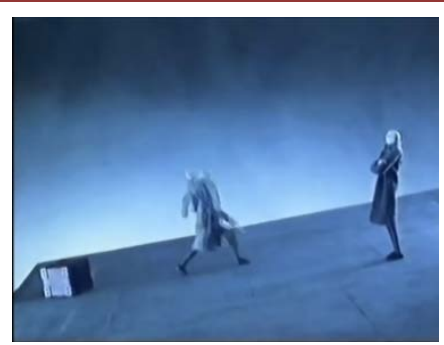
box have to stay away from the treasure box in order to avoid losing the balance of space.

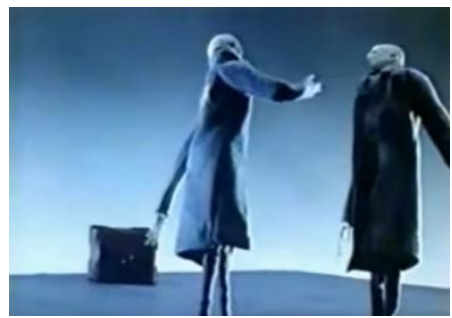

with each other.

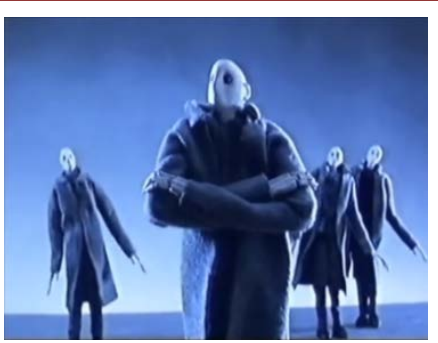

3. The character who wants the treasure box keeps going in the direction of the treasure box.

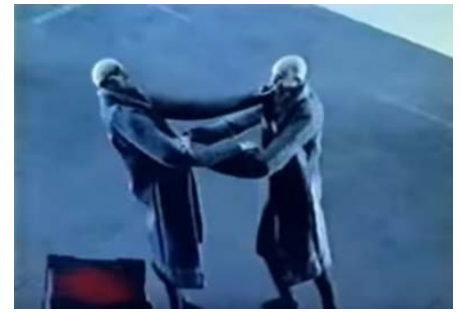

6. The fighting intensifies.

Source: https://www.youtube.com/watch?v=PADVHR-_wOs.

can be deduced from its content. It can be reversely deduced that if the symbol of the metaphor in Balance is not the treasure box, other "representatives of value and interest", such as diamonds, banknotes, or gold, can also serve as the representation of the metaphor; therefore, the metaphoric relationship has more a single referent. A referent logically analogized in context can be a symbol of reference if it is reasonably established in context.

In the case of Balance, the design of space is also an element of the metaphor. In order to maintain balance, the characters have to achieve an average distribution of gravity, and when imbalance appears, the viewer can interpret it as a metaphor of the broken or conflicting relationships between the characters. According to the first scene of the story, the originally distributed balance positions are located at the four corners, and when this balance is broken by the treasure box, it leads to conflict, and this imbalance and conflict become the key metaphor. Therefore, the author made an analogy between the unbalanced plane and the conflict (Figure 5).

If the perceptions between the two are compared according to their respective meanings, the analogy cannot be directly made with the mapping relationship, as their attributes have linked meanings, thus, the above cases cannot be supported in Gentner's theoretical model. When setting the theoretical model, Fauconnier and Turner set two different attributes at the input of different blocks, meaning the plane and conflicting elements are placed at two input terminals, 


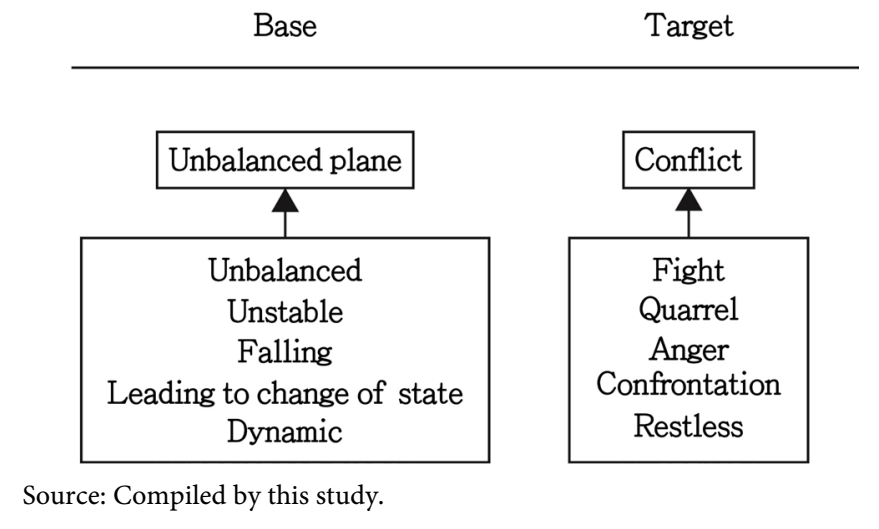

Figure 5. Relationship between the unbalanced plane and conflict.

and then, their attributes are transformed into the final metaphor result by entering the generic space. The conclusion of the analogy is that a metaphoric space with an imbalance is the conflict. The blending theory is supported in this case, as the final blended spaces include not only the attribute elements, as other external elements of the connotations are also involved in the whole metaphor. Figure 6 shows the process of the blending theory.

According to the blending theory of Figure 6, the final metaphor can indirectly connect the abstract concepts of the two through their original attributes, the link, and perception of the past experience, and even the factors of the psychological image. When the "conflict" is connected with the images of "curve" and "inclined", this is a signifier subject of visual psychology, and not merely a mapping of the metaphorical attributes. In summary, from Balance we can sum up three characteristics that constitute the metaphor of animated movies: Firstly, the mapping process includes original attributes, as well as experience elements in multiple channels, which may constitute a blended metaphoric space, and this argument is in line with Lakoff's view. Secondly, if the referent (treasure box) becomes the element of the metaphor in the narrative, according to the general cognition of popular definition, it can be judged by direct experience, and because this part is based on practical experience, establishment of the metaphor is simple and obvious; Thirdly, both the key element (treasure box) and the space (inclined plane) can be used as a symbol of the metaphor in the movie, meaning it can become an element of the metaphor, which also represents the simultaneous analogy of the multiple elements in the movie. Therefore, this paper discusses the space metaphor in the image in the following chapters.

\subsection{Case Study of the Extended Meanings of Metaphor Mapping in Space}

In Balance, the author created an unbalanced space to motivate the story to continue, thus, the key unbalanced plane is also an element of the metaphor. Regarding whether the space of an animated film can actually become the element of the metaphor, this chapter discusses the case of using space as the element of a metaphor. The construction of an animated film space must give the background 


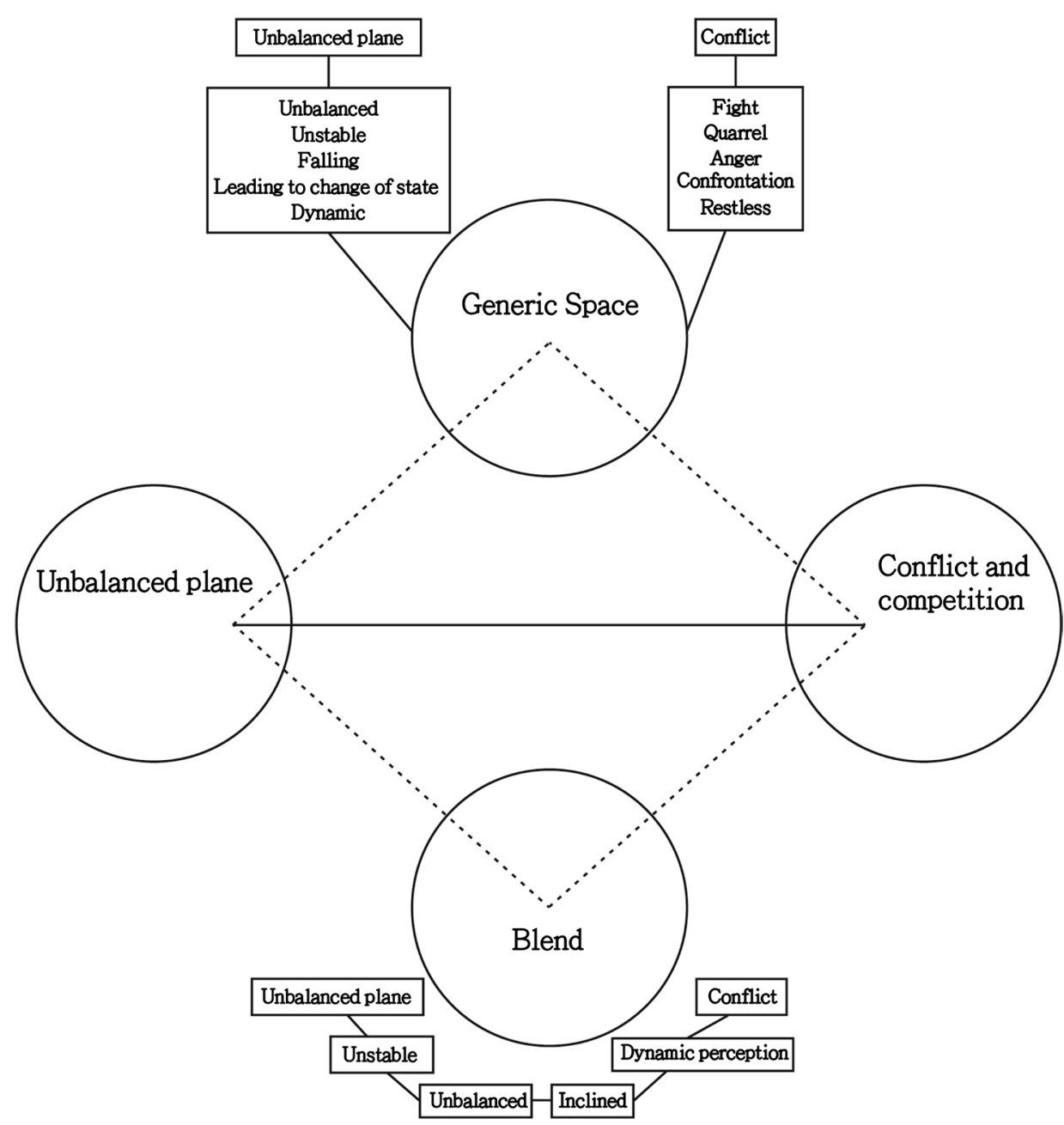

Source: Compiled by this study.

Figure 6. Analysis of the relation between the plane and the conflict with the blending theory.

of the narrative environment. The case of $L^{\prime} O N D E E$, a French animation, breaks the traditional idea that environment can only be a narrative background by using objects and phenomena as the metaphor of the described environment. The theory of ontological metaphors was proposed in Lakoff's Metaphors We Live $B y$, which pointed out that the metaphor of location and space is constructed in physical and cultural experience, like "high" and "upward" represents "happiness", "dignity", and "positivity" in experience. The link between the two is the recognition of experience, and the mapping relationship integrates experience and culture. Experiences and situations in life are accumulated constantly in the mind to form a system that links repetitive events with experience, systematically stores relevant concepts, and coalescences them together (Chang, 2012). According to the literature review, this paper conducted a case study of $L$ $O N D E E$ to illustrate the mapping relationship between metaphors in their extended meanings (Table 5).

The object of the metaphor in the scene of $L^{\prime} O N D E E$ is the change of mood. From the violent rain to the calm sky, from the dark to the bright, the viewer can 
have perceptions from sadness to joy, from tension to relaxation, tragedy to happiness, etc. Hints are also provided by the lens moving upward. As mentioned above, based on physical and cultural experience, the upward movement is a representation of "noble" and "positive". The mapping relationships can be collated, as shown in Figure 7.

Table 5. Description of rain turning to sunny and the scene of atmospheric change in $L^{\prime} O N D E E$.

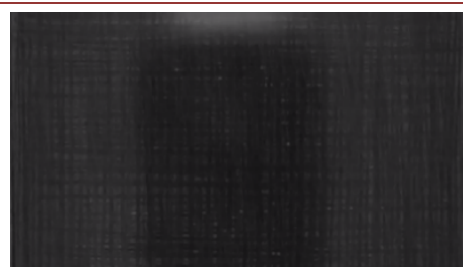

1. Distant view of the building.

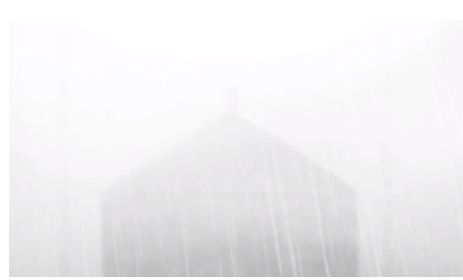

4. Clocks rising to the sky.

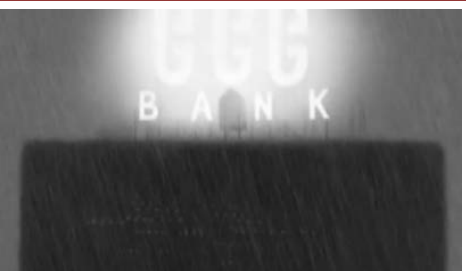

2. Signboards above the building (lightness is increased).

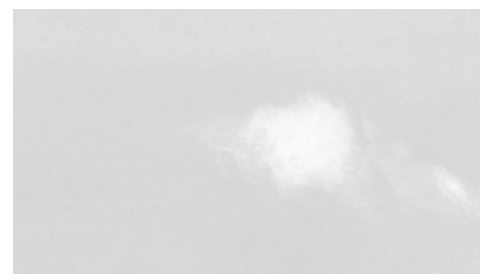

5. A calm sunny day.

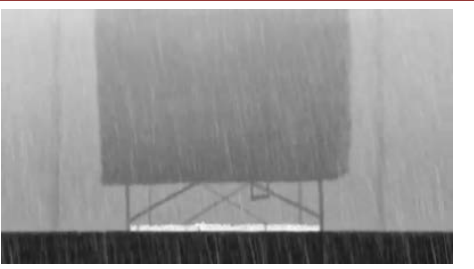

3. Birds waiting for sunshine under the water tower on the top floor.

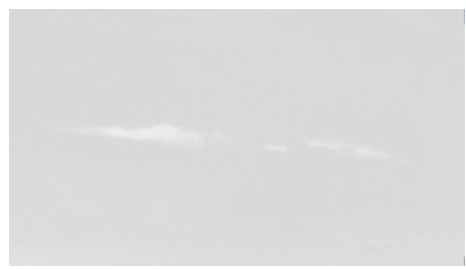

6. A calm sunny day.

Source: https://vimeo.com/53838485.

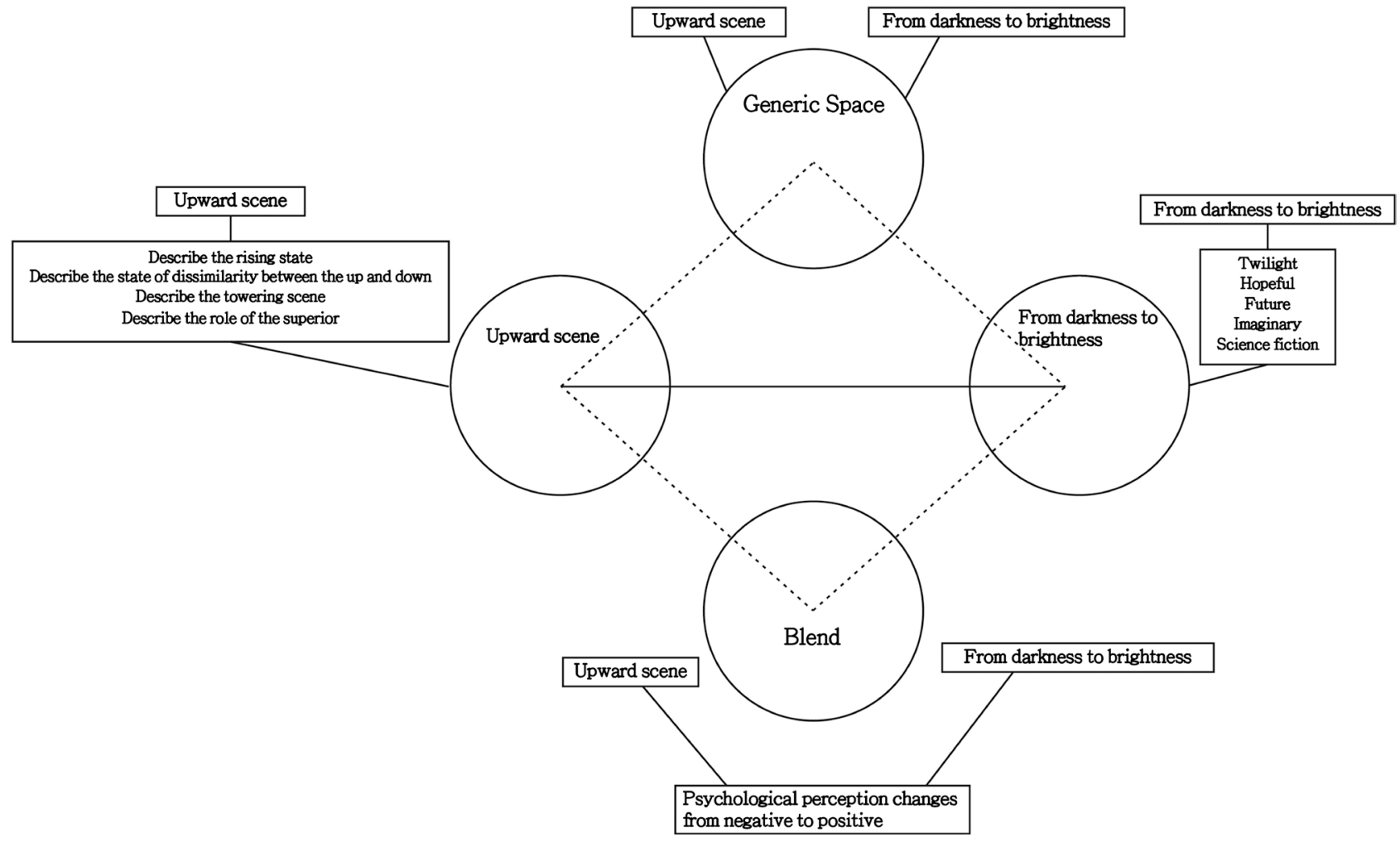

Source: Compiled by this study.

Figure 7. Metaphor mapping process of spaces in $L^{\prime} O N D E E$. 
The space moving upward and changing from dark to bright is a description of a phenomenon; they are not like the active performance of the characters, but the presentation of the phenomenon. The metaphor narrative is promoted by lens movement and the change of light and shadow in the scene. The mapping relationship is a process of simultaneous analogy with multiple attributes, including lens movement, light and shadow changes, and changes of the sound rhythm, and such combined perceptions constitute the representation of the whole metaphor. Movie art and linguistics are regarded as belonging to the same semiotic hierarchy: first, the composition of aesthetics must be considered; second, the camera movements and light effects will be superimposed over the denoted meaning (Metz, 1991).

Metz (1991). The art of film is located on the same semiological "plane" as literary art. The properly aesthetic orderings and constraints-versification, composition, and tropes in the first case; framing, camera movements, and light "effects" in the second-serve as the connoted instance, which is superimposed over the denoted meaning (p. 96).

Therefore, the metaphor of the essential meanings in the space is composed of the description of the phenomena. The above representations are all based on the change of time. The greatest difference between the metaphor of animation and the static image lies in the addition of time elements to construct the dynamic perception. The most important thing for animation is not movement, but the root cause that drives the movement (Whitaker \& Halas, 2013). From the time movement in $L^{\prime} O N D E E$, viewers could perceive that the lens is moving up diachronically, contributing to an upward feeling.

Another case of using space as the representation of a metaphor is NEGATIVE $S P A C E$, which is a French Film nominated for an Academy Award for the Best Short Film in 2018. In this film, the art of packing a suitcase is used as the metaphor of the relationship between the father and the leading character (Riganas, 2017). The author combined time and space as a metaphor of the time travel from the present back to the childhood memory (Table 6). The two spaces are linked by the present time (ready to drive) and the time travel to childhood (with the suitcase zipper analogized as the road). The mapping target is to achieve the representation of retrospective memory.

In this case, the change of time is metaphorized through the change of space, where the present action is connected with the past space-time background; therefore, the mapping relationship is the changing of the driving process into the suitcase used in the past. The analysis results of the original attributes of driving and the original attributes of the suitcase show that they are not in line with the narrative of the story. As the content above and below describes a state of recall, the connotations of the representative objects include the objects used now and in the past, which indirectly describes the differences between time and space. The mapping relationships can be collated, as shown in Figure 8.

Therefore, the corresponding target of the mapping relationship is to construct 
Table 6. Time-space transformation in NEGATIVE SPACE

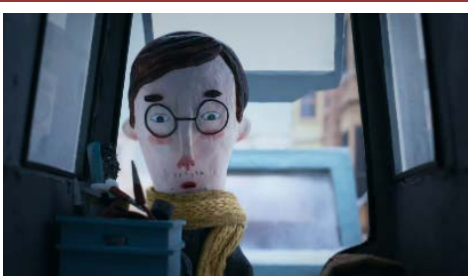

1. Close the door and get ready to drive.

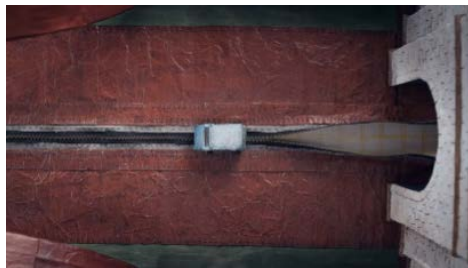

4. After leaving the tunnel, the road becomes the suitcase zipper.

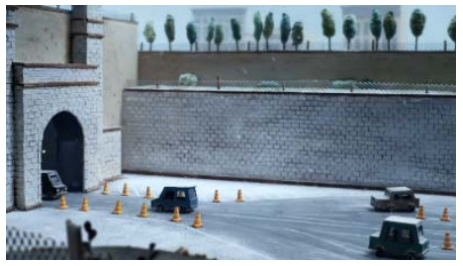

2. Drive toward the tunnel.

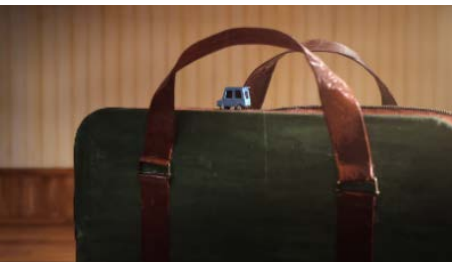

5. The car is driving on the suitcase.

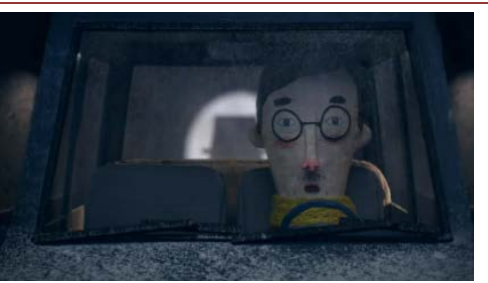

3. Pass through the tunnel.

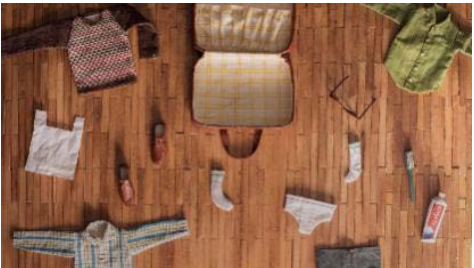

6. The suitcase is opened and it has traveled to a past time and space.

Source: https://vimeo.com/345922827.

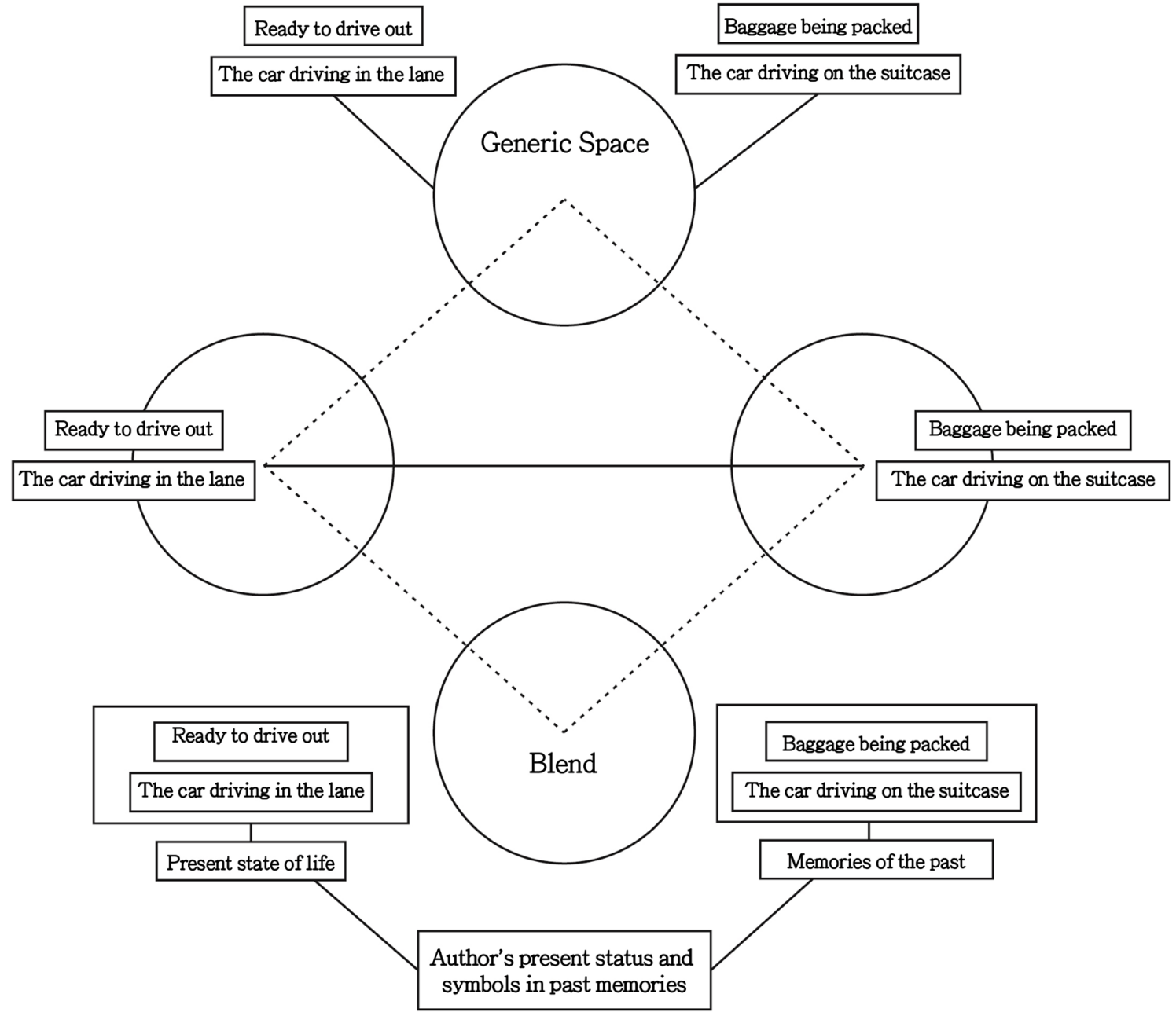

Source: Compiled by this study.

Figure 8. Mapping relation with space as the metaphor of time in NEGATIVE SPACE. 
the metaphoric meaning of the scene, as constructed in the context of story development. In terms of space, it is also a link between the real space and the imaginary space in the past. The author expressed the return to the past by the technique of "time travel" during driving. The car is the medium of the time travel, and a metaphor of the flow of time, while the zipper on the suitcase is used to replace the original road due to similarity in form, which creates visual continuity and is also a metaphoric symbol for the past in the time and space transformation. Therefore, the metaphor in NEGATIVE SPACE is a strong symbolic relationship that is strongly linked to memory. In short, substitution and symbolism are also techniques of metaphors. In comparison, the main technique used in The Employment (Figure 9) is the blending of the two attributes.

In summary, spatial metaphors transmit the reference target through the essence of objects. Its biggest difference with role play is that it describes the plot through simple phenomena, and also represents that the original attributes of objects must be transformed into the meaning of context. Even so, the essence of space will not change; for example, NEGATIVE SPACE made good use of space to express the concept of "traveling" time to give similar attributes to corresponding goals. The space is conceptualized into expressions of emotions or time and space, while all phenomena are presented through the guidance of the lens, such as the use of the upward movement of the lens in $L^{\prime} O N D E E$ to guide the viewers' emotions, or elaborate the space, as in the perspective of NEGATIVE $S P A C E$. In short, the lens plays the role of an interpreter of guidance and performance in a special metaphor. From the above point of view, the representations of the angle of view and the lens in animated movies also constitute the representative elements of the metaphor.

\section{Discussion}

The operation of an animated film metaphor is a process of hiding intuitive links and generating analogy through partial similar relations. The analogical basis includes not only the similarity in form, but also a reference of the meanings of

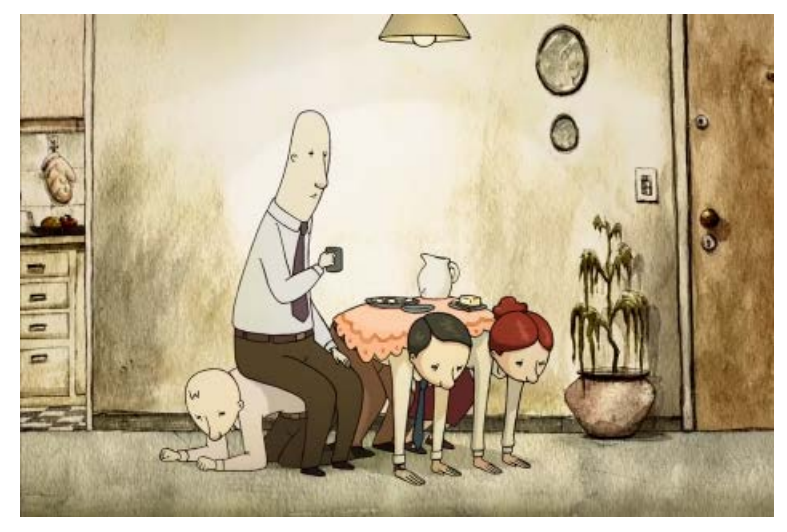

Source: https://vimeo.com/32966847.

Figure 9. Superposition of the trait of "Object" and the behavior attribute of "Man" applied in The Employment. 
specific symbols. The means of analogy hides in the message of the picture through substitution and symbolism. This paper collated the cases according to the mapping of metaphors in animated movies, and in addition to the attributes, the cognitive and psychological perceptions of past experience are mixed in the mapping process, making it a complex mixture that is difficult to demonstrate. From this point of view, the perception of metaphors is a multi-conditional correspondence, which forms the mapping relationship based on specific meanings to convey the whole "event". This paper summarizes the conditions of the metaphors in the case into the following five points:

1) The mapping relationship of popular symbols is a clear context of a metaphor.

This paper explored the symbols of the treasure box in the case of Balance, which is a common symbol under a popular definition. The meaning of the symbolic system is constructed based on the common cognition of the sender and the communicator. A visual design should avoid too many subjective factors and narrow the gap between the conveyed objectives (Su, Yen, \& Lee, 2007). Therefore, if the representative symbols of a metaphor can be represented by symbols commonly recognized by the public, the transmission can be understood more directly by the viewers.

2) Mapping with similarity in form can constitute a visual metaphor

The similarity of a visual metaphor is presented through intuitive form, which results in the linking of pictures. From the perspective of mapping, the references of common characteristics are captured to form a mapping relationship among them from the modeling composition.

3) Element substitution and attribute blending are the transmission modes of the mapping method

The mapping theory defines a metaphor as an analogical process of two elements, and a blended space illustrates the results of combining these two elements. The input ratio of the two elements determines whether the results of a metaphor are presented by means of substitution and symbolism. As in the case of NEGATIVE SPACE, the road is substituted by the zipper of the suitcase, while in The Employment, the attributes of "human" and "object" both coexist.

4) The lens is a guide of the metaphor

From the $L^{\prime} O N D E E$ case, it is concluded that the movement of the lens, editing, and time are not only the interpretation of the angle of view, but also the guide of the metaphor. A moving lens can reveal scenery and behavior, while switching the lens has the function of strengthening the relationship (Liu, Lee, \& Lee, 2018). Therefore, the process of a metaphor for a source and target guided by a lens is also a part of the factors that affect the perception of the viewers.

5) The metaphor of animated movies must be understood from the whole "event", in order to obtain a reasonable mapping relationship.

The common point in the above cases is the simultaneous mapping of multiple attributes. Simultaneous analogy in movies is a complex process of expres- 
sion when many elements are involved at the same time, because its constituent elements are not only a single message. In this case, many elements are broken down and analyzed. After combining the mapping relationships of all elements, through "holistic" observation, it is possible to construct the whole metaphorical targets of the events from different perspectives, which is also the basis for the rationality of context.

\section{Conclusion}

The metaphors of animated films have a mapping relationship construction based on its narrative content and past experience. In terms of the form of expression, apart from analogy by similarity, blending and substitution are the techniques of expression difficult to achieve in general real shot movies. To sum up the previous discussion, the mapping relation conveyed through corresponded metaphor performances, the representation from the graphical symbols and the scenes manipulated with cameras are able to contribute to the mapping form of the metaphor, which is triggered by the similarity of symbols and perception. This study explored dynamic metaphor representation with the mapping and blending theories, and conducted analysis and summarization on actual award-winning cases. However, metaphors cannot be generalized by the above cases. In addition to the link caused by pictures, in fact, understanding the processes of symbols and visual psychology are also factors to be considered in metaphors. Therefore, future scholars can conduct more in-depth discussions on the perceptual process of dynamic art from the perspective of the relationship between psychological perception and metaphoric symbols.

\section{Conflicts of Interest}

The authors declare no conflicts of interest regarding the publication of this paper.

\section{References}

Chang, R. H. (2012). Mental Space Theory and the Metaphorical Interpretations in Classical Chinese Discourse with Multiple Source Domains. Journal of Chinese Language Teaching, 9, 1-22.

Chi, L. R. (1992). Film Semiotics. Taipei City: Bookman Books.

ECO, U. (1976). A Theory of Semiotics (Vol. 217). Bloomington, IN: Indiana University Press. https://doi.org/10.1007/978-1-349-15849-2

ECO, U. (1990). Structuralism and Semiotics: Film Collections. Taipei City: Jiouda.

Fauconnier, G., \& Turner, M. (2008). The Way We Think: Conceptual Blending and the Mind s Hidden Complexities. New York: Basic Books.

Gannon, M. J. (2001). Cultural Metaphors: Readings, Research Translations, and Comentary: Sage.

Gentner, D. (1983). Structure-Mapping: A Theoretical Framework for Analogy. Cognitive Science, 7, 155-170. https://doi.org/10.1207/s15516709cog0702_3

Gibbs Jr., R. W. (2008). The Cambridge Handbook of Metaphor and Thought. Cam- 
bridge: Cambridge University Press. https://doi.org/10.1017/CBO9780511816802

Lakoff, G., \& Johnsen, M. (2003). Metaphors We Live by. London: The University of Chicago Press. https://doi.org/10.7208/chicago/9780226470993.001.0001

Liu, C. H., Lee, C. F., \& Lee, H. L. (2018). Effects of Shot Use and Role Action on Children's Viewing of a Picture Book Animation. Journal of Design, 23, 1-24.

Markman, A. B., \& Gentner, D. (2000). Structure Mapping in the Comparison Process. American Journal of Psychology, 113, 501-538. https://doi.org/10.2307/1423470

Metz, C. (1964). Le cinéma: Langue ou langage? Communications, 4, 52-90. https://doi.org/10.3406/comm.1964.1028

Metz, C. (1991). Film Language: A Semiotics of the Cinema. Chicago, IL: University of Chicago Press.

Riganas, N. (2017). Negative Space. https://www.imdb.com/title/tt7090150

Sajaniemi, J., \& Stützle, T. (2007). Lightweight Techniques for Structural Evaluation of Animated Metaphors. Interacting with Computers, 19, 457-471. https://doi.org/10.1016/j.intcom.2007.04.003

Su, W. C., Yen, J., \& Lee, C. F. (2007). Application of Semiotics and Cognitive Psychology to Visual Design. Journal of Humanities and Social Sciences, 3, 95-104.

Wang, H. H. (2012). Design by Metaphors. Taipei City: Sungoods Books.

Wen, K. H. (2010). An Introduction to Contemporary Western Rhetoric Theory. Taipei City: Bookman Books.

Whitaker, H., \& Halas, J. (2013). Timing for Animation. Boca Raton: CRC Press. 